\title{
Risk Factors, Pattern and Outcome of Motorcycle-associated Head Injury in Sokoto: An Analysis of 184 Cases
}

\author{
Henry Olayere Obanife ${ }^{1} \quad$ Nasiru Jinjiri Ismail ${ }^{2}$ Ali Lasseini ${ }^{2} \quad$ Bello B. Shehu ${ }^{2} \quad$ Ega J. Otorkpa ${ }^{3}$
}

${ }^{1}$ Department of Surgery, Division of Neurosurgery, College of Medical Sciences, University of Calabar, Calabar, Nigeria

${ }^{2}$ Regional Centre for Neurosurgery, Usmanu Danfodiyo University Teaching Hospital, Sokoto, Nigeria

${ }^{3}$ Department of Surgery, Division of Neurosurgery, University of Abuja Teaching Hospital, Abuja, Nigeria

Indian J Neurotrauma 2021;18:105-110.
Address for correspondence Henry Olayere Obanife, MBBS, MSc, FMCS, FWACS, Department of Surgery, Division of Neurosurgery, College of Medical Sciences, University of Calabar, Calabar 540271, Nigeria (e-mail: henrymendel@yahoo.com).

\begin{abstract}
Keywords

- motorcycle

- head injury

- Sokoto

- epidemiology

Background Road traffic accident (RTA) is the eighth leading cause of death worldwide. Motorcycle-associated head injury is the leading cause of road traffic associated morbidity and mortality in developing countries. Even though the incidence and mortality of head injury from motor cycle crash is on the increase in developing countries, especially in the African continent, most of the studies published in the literature on this subject matter took place in the developed Western countries.

Materials and Methods This was a retrospective cross-sectional study of data from patients managed in our institution between December 2014 and November 2016.

Results One hundred and eighty-four patients were analyzed. None of the patients used safety helmet for protection. The mean age was $27.6 \pm 17.2$ years with male female ratio of $6.7: 1$. Lone crash by cyclists and collisions accounted for $66.8 \%$ and $33.1 \%$ of the cases, respectively. Passengers and riders comprised $75 \%$ of the patients, while $25 \%$ were vulnerable pedestrians. The most frequently abused substance by the patients was tramadol (65.52\%). Severe head injury and pupillary abnormality were found in $23.9 \%$ and $45.5 \%$ of the patients, respectively. Cranial CT scan showed abnormalities in $40.2 \%$ of the patients. Surgery was done in $28.3 \%$ of the patients with mortality rate of $20.7 \%$.

Conclusions The use of motorcycle as a mean of transportation has caused significant negative impact on the society. Young people, who constitute the workforce, are majorly affected, and this invariably leads to a serious economic burden on the concerned families and communities.
\end{abstract}

\section{Introduction}

Road traffic accident (RTA) is the eighth leading cause of death worldwide; however, it is the third leading cause of death and the most common cause of disability in
Nigeria. ${ }^{1-5}$ Motorcycle-associated injuries are responsible for the majority of RTA and death in low-income countries. ${ }^{3}$ Most of the fatalities and disabilities that occur from RTA are due to traumatic head injuries., ${ }^{3,6}$ Overall, motorcycle-associated published online February 23, 2021
DOI https://doi.org/

$10.1055 / \mathrm{s}-0040-1722553$ ISSN 0973-0508.
(C)2021. Neurotrauma Society of India.

This is an open access article published by Thieme under the terms of the Creative Commons Attribution-NonDerivative-NonCommercial-License, permitting copying and reproduction so long as the original work is given appropriate credit. Contents may not be used for commercial purposes, or adapted, remixed, transformed or built upon. (https://creativecommons.org/licenses/by-nc-nd/4.0/). Thieme Medical and Scientific Publishers Pvt. Ltd. A-12, 2nd Floor, Sector 2, Noida-201301 UP, India 
head injury is the leading cause of road traffic associated head injuries in the developing countries (81\%). ${ }^{7}$ Research has shown that per mile travel, motorcycle riders have a 34 -fold higher risk of death in a crash than people driving other type of motor vehicles. ${ }^{8}$ Even though the incidence and mortality of head injury from motor cycle crash is on the increase in the developing countries, especially in the African continent, most of the studies published in the literature on this subject matter took pertained to the developed Western countries.

Head injury from motorcycle crash is most common among young men, due to the current economic uses of motorcycle in Nigeria. According to Solagberu et al, there are four reasons sustaining the use of motorcycles: cheaper cost (US \$500) compared with second hand cars (US \$3000); only means of transport to many streets, connecting roads, or villages; fast and can beat traffic jams in urban roads; and commercial operators make quick money. ${ }^{3}$

In Sokoto, motorcycle is the only means of intracity commercial transport system, making people of all age groups vulnerable. However, younger people are more predisposed to motorcycle-associated head injury because of their higher rate of mobility for socioeconomic and religious reasons. In Sokoto, primary school pupils, secondary and tertiary school students, government workers, and businessmen and women without private cars move around with commercial or private motorcycle. A finding in Ilorin, north-central Nigeria, showed that the majority of the motorcycle injury patients were students (people attending school as well as those in higher education 20.5\%) who were either passengers or pedestrians on journeys to and from school, while others were traders (17.9\%), artisans (17.0\%), and commercial cyclists (11.6\%). ${ }^{9}$

\section{Aim}

To study the clinical epidemiology and management outcomes of motorcycle-associated head injury in Sokoto.

\section{Materials and Methods}

This is a retrospective cross-sectional study using data of patients managed for motorcycle-associated head injuries between December 2014 and November 2016. Patients who discharged against medical advice; and patients who died before neurosurgical review were excluded. The following information was extracted from patients records and analyzed using Statistical Packages for the Social Sciences, version 20: sociodemographic characteristics of the patients, biomechanics of injuries, clinical features, and management outcomes.

\section{Results}

\section{Biographic Data}

A total of 205 patients were seen and managed in our institution during the study period, of which only 184 met the inclusion criteria for this study. Clinical history showed none of the patients used safety helmet. The mean age of occurrence of motorcycle-associated head injury was $27.6 \pm 17.2$ years (range
$1-71$ years). Most of the patients (81\% [149/184]) were age 40 years and below, while the remaining $19 \%$ (35/184) were above 40 years of age. There were $87 \%(160 / 184)$ males and $13 \%$ (24/184) females. Between the ages of 31 to 40 and $\geq 60$ years, no female was involved in the motorcycle RTA, whereas between the ages of 41 and 60 , more females than men were involved in motorcycle RTA ( $\bullet$ Table 1 and $\boldsymbol{- F i g . ~ 1 ) . ~}$

\section{Biomechanics of Injury and Substance Abuse Risks}

Loss of control of the motorcycle leading to a lone crash against stationary objects accounted for $66.8 \%(37 / 184)$ of the cases. Motorcycle versus motorcycle collision and motorcycle versus motor vehicle collision accounted for $20.1 \%$ (37/184) and $13 \%(24 / 184)$ of the cases, respectively. Motorcycle riders made up of $37.5 \%$ (69/184) of the patients, while passengers and pedestrians were $37.5 \%$ (69/184) and $25 \%$ (46/184) of the patients, respectively. There was history of substance abuse in $15.7 \%(29 / 184)$ patients, mostly by the riders. Tramadol accounted for $65.52 \%$ (19/29) of the substances abused, while cannabis and alcohol accounted for $20.69 \%$ (6/29) and 3.45\% $(1 / 29)$ of the substances abused, respectively. Other substances which were mostly not identified accounted for $10.34 \%$ (3/29) of substance abuse ( - Table 2 and $\boldsymbol{- F i g . ~}$ ).

Table 1 Sociodemographic characteristics of the patients

\begin{tabular}{|c|c|c|}
\hline Variable & Frequency $(n=184)$ & Percent \\
\hline \multicolumn{3}{|l|}{ Age (years) } \\
\hline$\leq 10$ & 31 & 16.8 \\
\hline $11-20$ & 43 & 23.4 \\
\hline $21-30$ & 46 & 25.0 \\
\hline $31-40$ & 29 & 15.8 \\
\hline $41-50$ & 13 & 7.1 \\
\hline $51-60$ & 13 & 7.1 \\
\hline$\geq 60$ & 9 & 4.9 \\
\hline \multicolumn{3}{|l|}{ Sex } \\
\hline Male & 160 & 87.0 \\
\hline Female & 24 & 13.0 \\
\hline
\end{tabular}

Mean age $=27.6 \pm 17.2$ years.



Fig. 1 Age-sex comparison of the patients. 
Table 2 Characteristics of the accidents as reported of patients

\begin{tabular}{|l|l|l|}
\hline Variable & Frequency $(\boldsymbol{n}=\mathbf{1 8 4})$ & Percent \\
\hline \multicolumn{2}{|l|}{ Mechanism of injury } & 66.8 \\
\hline $\begin{array}{l}\text { Lost handle } \\
\text { and fell }\end{array}$ & 123 & 20.1 \\
\hline $\begin{array}{l}\text { Collided with } \\
\text { another bike }\end{array}$ & 37 & 13.0 \\
\hline $\begin{array}{l}\text { Collided with } \\
\text { a car }\end{array}$ & 24 & 37.5 \\
\hline \begin{tabular}{l} 
Type of injury \\
\hline Rider
\end{tabular} & 69 & 25.0 \\
\hline Passenger & 46 & 37.5 \\
\hline Pedestrian & 69 & \\
\hline
\end{tabular}

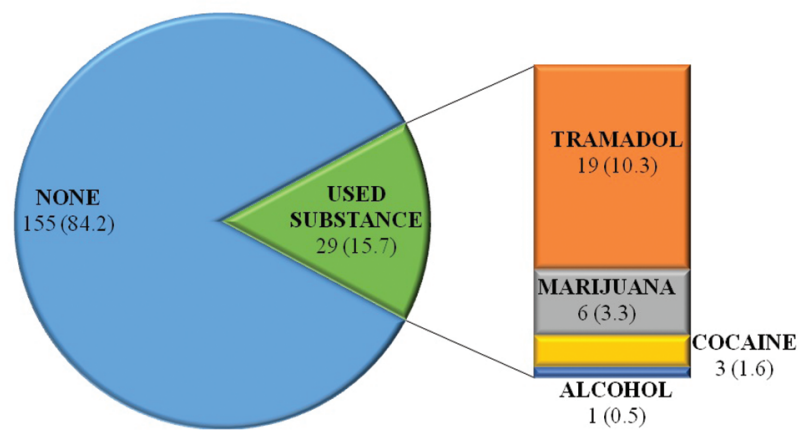

Fig. 2 Substance abuse among patients.

\section{Clinical Assessments, Management and Follow-up Information}

Majority of the patients (41.8\% [77/184]) had moderate head injury, followed by mild head injury (34.2\% [63/184]). Severe head injury occurred in $23.9 \%$ (44/184) of the patients. Pupillary abnormalities were seen in $45.5 \%$ of the patients. While unequal pupils were seen in $26.1 \%$ (48/184) cases, bilateral pupillary dilatation was seen in $17.4 \%$ (32/184) patients. Injuries in non-neurological organ systems occurred in only $6.5 \%$ of the patients. In $4.9 \%(9 / 184)$ patients, only one organ system, mostly the chest, was involved, whereas in 1.6\% (3/184), two or more organ systems were involved. Radiological assessment of intracranial injuries was impossible in 20.7\% (38/184) patients either as a result of lack of funds conduct brain CT scan or the scanner was not functional at the time of presentation. Above 39 percent (39.1\% [72/184]) of the patients had normal findings on CT scan, while $40.2 \%$ (30/184) of the patients had various forms of pathologies seen, with 16.3\% (30/184) having extra-axial blood clots. Above 71 percent of the patients (71.7\% [132/184]) underwent nonoperative treatment, while $28.3 \%$ (52/184) patients underwent operative treatment. Above 11 percent of the patients (20.7\% [52/184]) died, while 79.3\% (146/184) survived. Thirty-seven percent (54/184) patients stopped follow-up visits in the outpatient clinic after 1 to 3 visits, while $56.2 \%(82 / 184)$ patients attended outpatient clinic for follow-up between 4 to 6 appointments. Only 6.8\% (10/184) continued follow-up clinic attendance up to weeks ( - Tables 3 and $\mathbf{4}$ ).
Table 3 Clinical assessment of patients

\begin{tabular}{|c|c|c|}
\hline Variable & Frequency $(n=184)$ & Percent \\
\hline \multicolumn{3}{|l|}{ Glasgow coma scale } \\
\hline Mild (> 12) & 63 & 34.2 \\
\hline $\begin{array}{l}\text { Moderate } \\
(9-12)\end{array}$ & 77 & 41.8 \\
\hline Severe ( 8 ) & 44 & 23.9 \\
\hline \multicolumn{3}{|l|}{ Pupils } \\
\hline Normal & 104 & 56.5 \\
\hline Unequal & 48 & 26.1 \\
\hline $\begin{array}{l}\text { Dilated } \\
\text { bilaterally }\end{array}$ & 32 & 17.4 \\
\hline \multicolumn{3}{|l|}{ Comorbidity } \\
\hline None & 172 & 93.5 \\
\hline $\begin{array}{l}\text { One organ } \\
\text { system }\end{array}$ & 9 & 4.9 \\
\hline $\begin{array}{l}\text { Two or more } \\
\text { organ systems }\end{array}$ & 3 & 1.6 \\
\hline \multicolumn{3}{|l|}{ Hematomas } \\
\hline No CT & 38 & 20.7 \\
\hline No abnormality & 72 & 39.1 \\
\hline Extradural & 20 & 10.9 \\
\hline Subdural & 10 & 5.4 \\
\hline Intracerebral & 9 & 4.9 \\
\hline Intraventricular & 3 & 1.6 \\
\hline Subarachnoid & 2 & 1.1 \\
\hline $\begin{array}{l}\text { Hemorrhagic } \\
\text { contusions }\end{array}$ & 30 & 16.3 \\
\hline
\end{tabular}

Table 4 Management and follow-up of patients

\begin{tabular}{|c|c|c|}
\hline Variable & Frequency $(n=184)$ & Percent \\
\hline \multicolumn{3}{|c|}{ Type of management } \\
\hline Nonoperative & 132 & 71.7 \\
\hline Operative & 52 & 28.3 \\
\hline \multicolumn{3}{|l|}{ Outcome } \\
\hline Alive & 146 & 79.3 \\
\hline Dead & 52 & 20.7 \\
\hline \multicolumn{3}{|c|}{ No. of follow-up visits $(n=146)$} \\
\hline $1-3$ & 54 & 37.0 \\
\hline $4-6$ & 82 & 56.2 \\
\hline $7-10$ & 10 & 6.8 \\
\hline
\end{tabular}

Note: Mean no. of follow-up visits $=3.9 \pm 1.6$.

\section{Discussion}

This is a retrospective cross-sectional study on patients seen and managed in our institution between December 2014 and November 2016. Two hundred and five patients were managed: six patients died at the Accident and Emergency Department during resuscitation and fifteen patients 
discharged against medical advice. Both were excluded from this study. The remaining 184 patients met the inclusion criteria for this study. The mean age of the patients was 27.6 years (standard deviation $[\mathrm{SD}]=17.2$ ) with an age range between 1 to 71 years. This is slightly lower than the mean age in a similar study in Ibadan, Nigeria (33.1 years with $S D=18.3$ ). ${ }^{3}$ Previous studies showed male preponderance. A study in Cambodia showed male-to-female ratio of 5:1 for patients between the ages of 11 to 20 years and 6:1 for patients between the ages of 21 to 30 years, respectively. ${ }^{7}$ A study in Ibadan showed male-to-female ratio of approximately $5: 1 .^{10}$ These ratios are consistent with our finding of $87 \%$ males and $13 \%$ females (ratio 6.7:1). However, studies from high income countries showed smaller male-to-female ratios., ${ }^{7,911,12}$ This high frequency of motorcycle-associated head injury among men is perhaps due to the fact that men are more frequently engaged in commercial activities in many cultures in the developing countries, especially countries in Africa where the bulk of this problem resides.

Motorcycle-associated head injury is mostly seen common among young and energetic people, as observed in this study, with $81 \%$ of the patients between the ages of 1 to 40 years. Similarly, Peeters et al reported a frequency of $84.5 \%$ among people between 11 and 30 years of age. ${ }^{7}$ However, recent studies in high-income countries showed a notable shift in the motorcycle-associated head trauma population toward older age groups. ${ }^{7,911,12}$ A very notable finding in this study is that patients' sex was a major determinant of age distribution of motorcycle-associated head injuries: between the ages of 31 to 40 and 60 years and above, no female patient was involved in the motorcycle RTA, whereas between the ages of 41 and 60 , more females than males were involved in motorcycle RTA (-Table $\mathbf{1}$ and - Fig. $\mathbf{1}$ ).

Gabella et al found that after adjusting for age and crash characteristics, nonhelmeted riders were 2.4-times more likely than those wearing a helmet to sustain brain injuries or skull fractures, while Rowland et al in the following year found that after adjusting for collision type, speed limits, and environmental factors, nonhelmeted riders had a 3.1-fold increased risk of head injuries or death compared with helmeted riders. ${ }^{13,14}$ These two studies highlighted the pivotal role of safety helmet in preventing head injuries by riders and passengers of motorcycles. Despite these research findings and various campaigns against nonuse of helmet by motorcycle riders and passengers in many countries, compliance by to helmet use by cyclists remain a huge challenge, especially in developing countries. In Nigeria, according to the sector Commander of the Federal Road Safety Corps, Hyginus Omeje, the national road traffic standard is that motorcycle riders must wear a crash helmet and must ride with a retroreflective jacket, especially at night; hence, there have been traffic checks and campaigns have been organized by the officers of the Federal Road Safety Corps of Nigeria on use of helmet. ${ }^{13}$ Despite these efforts, noncompliance with regard to the use of safety helmet remain very prevalent in Nigeria. None of the patients in this study used safety helmet and the same was found in a study in Ilorin, Nigeria. ${ }^{3}$ This lack of compliance with respect to the use of safety helmet is reflective of how there are currently no national laws enacted in the Nigeria parliament on the use of safety helmet. However, due to a stringent law on compulsory use of helmets in Vietnam, there has been a decrease in the trend of traumatic brain injuries (TBI) from less than $40 \%$ to nearly $100 \%{ }^{13}$

The mechanisms of injury in motorcycle accident were by lone crash or collision. A relatively large number of patients in this study were involved in a motorcycle accident by way of lone crash by the riders (66.8\%). Collision occurred either by motorcycle versus motorcycle $(20.1 \%)$ or by motorcycle versus motor vehicle (13\%). Both lone crashes and collisions had the following identical underlying factors: inexperience, machismo behaviors in young people, and/or substances abuse. There exists a competition to showcase riding skills and ability to carry passengers by commercial riders, mainly coming about as a result of machismo behaviors common among young riders. These are corroborated by various research findings: Soderstrom et al found that the overrepresentation of young riders in motorcycle injuries was due to inexperience in riding a motorcycle or a higher exposure to riding, while others found that the risk-taking characteristics of young riders, including speeding, running yellow light and drinking while riding contributed to the high risk of motorcycle injuries. ${ }^{15-17}$

Drinking and driving is one of the leading causes of motorcycle-associated head injuries, resulting in significant death and disability. ${ }^{18}$ According to the United States' National Highway and Safety Administration (NHSTA), there were approximately 30 deaths per day in 2017 due to drunk riding and an intoxicated motorcyclist involved in a crash was 28 times more likely to die than passenger car occupants per miles driven. ${ }^{15,19}$ Besides alcohol, $32 \%$ of motorcycle riders treated in Maryland trauma centers during 1990-1991 had used marijuana (cannabis) prior to the crash, which was significantly higher than the $2.7 \%$ of car drivers. ${ }^{20,21}$ Among the $15.7 \%$ with history of substances abuse in this study, $3.45 \%$ and $20.7 \%$ abused alcohol and marijuana (cannabis), respectively, and had consumed these drugs before riding. However, the most frequently abused substance in this study was tramadol (65.5\%), which is an emerging drug of abuse in Nigeria in recent years. In a study in a neuropsychiatric hospital in Maiduguri, Nigeria, the prevalence of tramadol abuse was $54.4 \%$ and the most common reason for abuse was to relieve tiredness. ${ }^{22}$ In Ilorin, Nigeria, the finding was that most of the patients were riders (53.6\%), while passengers and pedestrians comprised $32.1 \%$ and $14.3 \%$, respectively. ${ }^{13}$ In this study, riders and pedestrians were equally affected (37.5\% each), while passengers comprised $25 \%$ of the patients. Children and elderly women were the most vulnerable pedestrians.

The most common type of head injury in this study (based on classification by Glasgow coma scale [GCS]) was moderate head injury (41.8\%). While mild head injury is second most common, accounting for $34.2 \%$ of the cases, severe head injury is the least common (23.9\%). This is incongruous with a previous study, which found that $80 \%$ of patients with head injuries sustained minor head injury. ${ }^{23}$ We found associated injuries in other non-neurological systems in $6.5 \%$ of patients, 
which is also at variance to what was found in previous studies, especially in Ibadan, with as high as $20.8 \%$ in pelvis and long bones alone. ${ }^{24}$

Cranial CT scan was done on $79.3 \%$ of our patients, while the remaining $20.7 \%$ patients could not do cranial CT scan due to a lack of finances, leading to an inability to make radiological diagnoses in this set of patients (20.7\%). This finding was congruous with the study in Ibadan, Nigeria, where cranial CT scan was obtained in $72.2 \%$ of patients with head injuries. ${ }^{10}$ Among those who had brain CT scan in this study, only $40.2 \%$ had abnormal radiological findings. Extradural haematoma was seen in $10.9 \%$, hemorrhagic contusions was seen in $16.3 \%$, subdural haematoma was seen in $5.4 \%$, traumatic subarachnoid hemorrhages was seen in $1.1 \%$, intracerebral hemorrhages was seen in $4.9 \%$, and intraventricular bleed seen in $1.6 \%$ of the cases. However, in a study by Adeleye et al, brain CT scan revealed possible surgical lesions like extensive brain contusions in $18.8 \%$, acute extradural hematoma in $4.1 \%$, acute subdural hematoma in $3.8 \%$, traumatic intracerebral hemorrhage in $3.2 \%$, and pneumocephalus in $1.0 \%{ }^{24}$ While extra-axial bleed was the most common radiological findings in our study (16.3\%), brain contusions were the most frequent radiological finding in Ibadan (18.8\%). ${ }^{24}$ In other similar studies traumatic subarachnoid hemorrhage was the most common CT finding in TBI, occurring in approximately 30 to $40 \%$ of patients with moderate-to-severe TBI, and $5 \%$ of patients with minor TBI. ${ }^{25-28}$

Operative treatment was performed in $28.3 \%$ patients, with procedures ranging from wound debridement, duroplasty, cranioplasty, trauma flap craniotomy, and decompressive hemicraniectomy In a similar study, only $13.1 \%$ received operative care, while another $6.8 \%$ with surgical lesions either died before surgery was performed or refused consent. ${ }^{10}$ Our mortality rate of $20.7 \%$ was congruous with another finding from a similar study in this environment, with mortality rate of $23.9 \%{ }^{10}$ Follow-up was significantly erratic, with mean follow-up visits of $3.9 \pm 1.6$ times. This was inadequate to measure longtime changes.

\section{Conclusions}

The use of motorcycle as a mean of transport has caused more negative than positive impact on the Sokoto community. Motorcycle-associated head injury is mainly predominant among young male residents who constitute the major workforce within the catchment areas of the study population. The high morbidity and mortality rate seen in this study showed that there was a significant loss of manpower within the community, thereby increasing the population of dependents and future beggars in the streets. Noncompliance with regard to the use of safety helmet seen in this study and similar studies in this environment have led to an increased incidence compared with places where the use of helmet is enforced by the government; therefore, there is the need for national laws to be enacted and enforced to reduce the incidence and severity of injuries.

Conflict of Interest

None declared.

\section{References}

1 Abbas AK, Hefny AF, Abu-Zidan FM. Does wearing helmets reduce motorcycle-related death? A global evaluation. Accid Anal Prev 2012;49:249-252

2 Ekere AU, Yellowe BE, Umune S. Surgical mortality in the emergency room. Int Orthop 2004;28(3):187-190

3 Solagberu BA, Adekanye AO, Ofoegbu CP, Udoffa US, Abdur-Rahman LO, Taiwo JO. Epidemiology of trauma deaths. West Afr J Med 2003;22(2):177-181

4 Akinpelu VO, Oladele AO, Amusa YB, Ogundipe OK, Adeolu AA, Komolafe EO. Review of road traffic accident admissions in a Nigerian tertiary hospital. East Cent Afr J Surg 2006;12:63-67

5 Nwadinigwe CU, Onyemaechi NO. Lethal outcome and time to death in injured hospitalised patients. Orient J Med 2005;17:28-33

6 Chichom-Mefire A, Atashili J, Tsiagadigui JG, Fon-Awah C, Ngowe-Ngowe M. A prospective pilot cohort analysis of crash characteristics and pattern of injuries in riders and pillion passengers involved in motorcycle crashes in an urban area in Cameroon: lessons for prevention. BMC Public Health 2015;15:915

7 Peeters S, Blaine C, Vycheth I, Nang S, Vuthy D, Park KB. Epidemiology of traumatic brain injuries at a major government hospital in Cambodia. World Neurosurg 2017;97:580-589

8 Amoros E, Martin JL, Laumon B. Under-reporting of road crash casualties in France. Accid Anal Prev 2006;38(4):627-635

9 Roozenbeek B, Maas AIR, Menon DK. Changing patterns in the epidemiology of traumatic brain injury. Nat Rev Neurol 2013;9(4):231-236

10 Adeleye AO, Clark DJ, Malomo TA. Trauma demography and clinical epidemiology of motorcycle crash-related head injury in a neurosurgery practice in an African developing country. Traffic Inj Prev 2019;20(2):211-215

11 Maas AI, Stocchetti N, Bullock R. Moderate and severe traumatic brain injury in adults. Lancet Neurol 2008;7(8):728-741

12 Langlois JA, Sattin RW. Traumatic brain injury in the United States: research and programs of the Centers for Disease Control and Prevention (CDC) J Head Trauma Rehabil 2005;20(3):187-188

13 Solagberu BA, Ofoegbu CKP, Nasir AA, Ogundipe OK, Adekanye AO, Abdur-Rahman LO. Motorcycle injuries in a developing country and the vulnerability of riders, passengers, and pedestrians. Inj Prev 2006;12(4):266-268

14 Ankarath S, Giannoudis PV, Barlow I, Bellamy MC, Matthews SJ, Smith RM. Injury patterns associated with mortality following motorcycle crashes. Injury 2002;33(6):473-477

15 Jung $S$, Xiao Q, Yoon Y. Evaluation of motorcycle safety strategies using the severity of injuries. Accid Anal Prev 2013;59:357-364

16 Chesham DJ, Rutter DR, Quine L. Motorcycling safety research: a review of the social and behavioral literature. Soc Sci Med 1993;37(3):419-429

17 Lin MR, Chang SH, Pai L, Keyl PM. A longitudinal study of risk factors for motorcycle crashes among junior college students in Taiwan. Accid Anal Prev 2003;35(2):243-252

18 Aptel I, Salmi LR, Masson F, Bourdé A, Henrion G, Erny P. Road accident statistics: discrepancies between police and hospital data in a French island. Accid Anal Prev 1999;31(1-2):101-108

19 Lin MR, Kraus JF. A review of risk factors and patterns of motorcycle injuries. Accid Anal Prev 2009;41(4):710-722

20 Soderstrom CA, Dischinger PC, Kerns TJ, Trifillis AL. Marijuana and other drug use among automobile and motorcycle drivers treated at a trauma center. Accid Anal Prev 1995;27(1):131-135 
21 Cimbura G, Lucas DM, Bennett RC, Donelson AC. Incidence and toxicological aspects of cannabis and ethanol detected in 1394 fatally injured drivers and pedestrians in Ontario (1982-1984). J Forensic Sci 1990;35(5):1035-1041

22 Ibrahim AW, Yerima MM, Pindar SK, et al. Tramadol abuse among patients attending an addiction clinic in north-eastern Nigeria: outcome of a four year retrospective study. Adv Psychol Neurosci 2017;2(2):31-37

23 Pandor A, Goodacre S, Harnan S, et al. Diagnostic management strategies for adults and children with minor head injury: a systematic review and an economic evaluation. Health Technol Assess 2011;15(27):1-202

24 Adeleye AO, Ogun MI. Clinical epidemiology of head injury from road-traffic trauma in a developing country in the current era. Front Neurol 2017;8:695
25 Stiell IG, Wells GA, Vandemheen K, et al. The Canadian CT head rule for patients with minor head injury. Lancet 2001;357(9266):1391-1396

26 Steyerberg EW, Mushkudiani N, Perel P, et al. Predicting outcome after traumatic brain injury: development and international validation of prognostic scores based on admission characteristics. PLoS Med 2008;5(8):e165, discussion e165

27 Roberts I, Yates D, Sandercock P, et al; CRASH trial collaborators. Effect of intravenous corticosteroids on death within 14 days in 10008 adults with clinically significant head injury (MRC CRASH trial): randomised placebo-controlled trial. Lancet 2004;364(9442):1321-1328

28 Muhammad M, András V. Motorcycle fatalities in Malaysia. IATSS Res 2012;36:30-39 